Revue des sciences religieuses 90 no 4 (2016), p. 491-516.

\title{
EL OP. 38 CENT NOMS DE DÉU DE RAMON LLULL COMO POESÍA ANTICORÁNICA ${ }^{1 *}$
}

\section{LAS «IMPERFECCIONES» MÉTRICAS DEL OP. 38 CENT NOMS DE DÉ $U^{2}$}

El op. 38 Cent noms de Déu es una obra poética de Ramon Llull dedicada a la alabanza de Dios a través de sus atributos, presentados

1. Le lecteur trouvera p. 515-516 une présentation en français de l'article d'O. de la Cruz Palma

${ }^{*}$ Este trabajo ha sido elaborado dentro de la actividad del proyecto de investigación consolidado 2014 SGR 53 de la AGAUR de la Generalitat de Catalunya.

La transcripción de palabras árabes se hace de acuerdo con los criterios de la Encyclopédie de l'Islam (EI²). Para las citas de pasajes coránicos (abreviados con Q.), utilizamos la traducción de J. CoRTÉs, El Corán, Barcelona, 2002. Para la enumeración de las obras de Ramon Llull, seguimos el catálogo fijado por F. DomínGUEZ REBOIRAS, « Ramon Lull, Works », A. Fidora - J. E. Rubio (eds.), Raimundus Lullus. An Introduction to his Life, Works and Thought, Turnhout, 2008, pp. 135-242. Utilizamos a menudo las abreviaturas NEORL (Palma de Mallorca) para la citar colección de las obras catalanas de Ramon Llull Nova Edició de les Obres de Ramon Llull, y ROL para la de las obras latinas Raymundi Lulli Opera Latina (Turnhout).

2. La descripción de las estrofas se puede encontrar en varios trabajos : R. D'ALòsMoner, Ramon Llull, Poesies, col. Els Nostres Clàssics (ENC) 3, Barcelona, 1925, p. 11 (traducción propia del catalán) : «Los trescientos versos (sic por 3000) de esta obra de tema teológico son en tercetos monorrimos y dispuestos en cien capítulos. Es de imitación árabe. Dentro de su monotonía, se encuentran algunas pocas páginas de lectura amable. Su prólogo tiene interés. Estaban destinados a ser cantados como los Salmos ». J. MAssó TORRENTS, Repertori de l'Antiga Literatura Catalana, vol. I : La poesia, Barcelona, 1932, p. 281 (trad. propia del catalán) : «Cada alabanza de un nombre va seguida de unos treinta versos, y, como hace cien, suman 3000 ; es cierto que algunas alabanzas no llegan a este número ( 27 versos), pero otras lo sobrepasan (32 versos). Las rimas forman siempre tres versos iguales. Cada alabanza de tres en tres versos va precedida de una admiración : ¡Oh Deus ! que, naturalmente, va cambiando según el apelativo [motivo de la alabanza]». J. M. VIDAL I RoCA, "Sobre Els cent noms de Déu. Aspectes de teonomàstica lul·liana », Studia Lullistica et Philologica. Miscellanea in honorem Francisci B. Moll et Michaelis Colom, Maioricensis Schola Lullistica, Palma de Mallorca, 1990, pp. 97-114; cit. p. 100 (trad. propia del cat.) : «En total son diez mil trescientos versos monorrimos plurimétricos, distribuidos generalmente de diez en diez en los cien capítulos (hay dos - el XXI y el XVII - que sólo tienen nueve; siete -VII, XXVIII, XLIX, L, LI, LXVII, XCI - y once, y el explicit 
aquí como nombres de Dios. Su propio título hace evidente la relación de esta obra con la tradición islámica de los 99 nombres de Dios o de los nombres más bellos (al-asmā'al-husnāa). Si bien después haremos una introducción a esta cuestión, avanzaremos que, en cuanto a la intención que Ramon Llull tenía al redactar esta obra, hay que tener en cuenta en todo momento el prólogo, que damos a continuación acompañado de la traducción latina, hasta el momento inédita :

\begin{tabular}{|c|c|}
\hline & $\begin{array}{l}\text { iste liber de centur } \\
\text { Prologus. }\end{array}$ \\
\hline $\begin{array}{l}\text { 2. Con los sarraíns entenen pro } \\
\text { lur lig esser donada de Deu, per } \\
\text { car l'Alcorà es tam bel dictat c } \\
\text { no'l poria fer nuyl hom sembl } \\
\text { d'él, segons que els dien, yo, Ram } \\
\text { Luyl indigne, me vuyl esforsar, } \\
\text { ajuda de Deu, fer aquest libre, en } \\
\text { ha meyllor materia que en l'Alcor } \\
\text { significar que enaxí com yo fas li } \\
\text { de meyllor materia que l'Alco } \\
\text { pot esser altre home qui aquest li } \\
\text { pos en axí bel dictat com l'Alco } \\
\text { E assò fas per so que hom pus } \\
\text { argüir als sarraíns que l'Alcorà no } \\
\text { dat de Deu; ja sia que sia bel dic } \\
\text { Emperò deim que aquest libre, e } \\
\text { be, es donat de Deu, segons que } \\
\text { se cové. Soplec doncs al sant Pa } \\
\text { Apostoli e als seynors cardenals qu } \\
\text { fassen posar en latí en bel dictat, }\end{array}$ & $\begin{array}{l}\text { 2. Cum Sarraceni ex pulchro } \\
\text { dictamine quo liber Alkoram est } \\
\text { conscriptus, cui similem nullus } \\
\text { mortalium, ut ipsi asserunt, efficere } \\
\text { potuisset, probare intendant eorum } \\
\text { legem a Deo emanare, ego Raymundus } \\
\text { Lull, licet indignus, Dei tamen auxilio } \\
\text { fretus, hunc librum componere conor, } \\
\text { in quo melior materia habetur quam in } \\
\text { Alkoram, ut ex eo coniri possit quod, } \\
\text { sicut ego de meliore materia librum } \\
\text { conficio quam sit illa quae habetur } \\
\text { in Alkoram, ita fieri potest ut alius } \\
\text { homo bene eundem libellum aeque } \\
\text { pulchro et eleganti dictet stylo, prout } \\
\text { est dictatus liber Alkoram. Et hoc ea } \\
\text { efficio intentione ut possint Sarraceni } \\
\text { redargui librum Alkoram, quantumuis } \\
\text { pulchro procedat stilo, non fuisse } \\
\text { datum a Deo. Dicimus tamen hunc }\end{array}$ \\
\hline
\end{tabular}

que consta de cinco, según la edición de las Obres de Ramon Llull-ORL), todos ellos acabados con la misma cantinela latina : Laus et honor essentie Dei et diuinis personis et dignitatibus earum. Et recordemur et amemus Ihesum Naçarenum et Mariam uirginem matrem eius ». A. I. PeIRATS NAVARro, "El Liber de centum nominibus Dei o Cent noms de Déu de Ramon Llull : per a una edició crítica », S. Martí - M. Cabré - F. Feliu - N. Iglésias - D. Prats (eds.), Actes del XIIIè Colloqui Internacional de Llengua $i$ Literatura Catalanes, Universitat de Girona, 8-13 de setembre de 2003, Publicacions de l'Abadia de Montserrat, Barcelona, 2007, vol. III, pp. 297-310, cit. pp. 303-304 (trad. propia del cat.) : « [la versión catalana] en versos aniososilábicos, que oscian entre 7 y 11 sílabas, según exigencias métricas, en disposición estrófica de tercetos monorrimos de rima oxítona regular, excepto dos casos [sc. 2. Essencia y 16. Vida], en donde el mismo nombre atribuido de la dignidad implicaba ya rima paroxítona », y añade en la nota 7 : «Et ritmo será siempre constante, así como la rima, sin que ello implique una recurrencia a rimas forzosas o imperfectas, como ocurre con la traducción latina ». 


\begin{tabular}{|c|c|}
\hline $\begin{array}{l}\text { yo no li sabria posar, per so car ignor } \\
\text { gramàtica. E si yo en alcuna cosa erre } \\
\text { en est libre contra la fe, sotsmet lo dit } \\
\text { libre a correcció de la sancta Ecclesia } \\
\text { romana. }\end{array}$ & $\begin{array}{l}\text { librum et omne datum optimum a Deo } \\
\text { esse, prout asserere et fateri oportet. } \\
\text { Qua propter ego Raymundus Lullius } \\
\text { obsecro sanctum Patrem apostolicum } \\
\text { et dominos cardinales iubeant ipsum } \\
\text { latine reddi. Id enim a me effici } \\
\text { nequam cum sim grammatice ignarus. } \\
\text { Et si in aliquo contra fidem errauero, id } \\
\text { et librum predictum submitto correc- } \\
\text { tioni sanctae Romanae Ecclesiae. }\end{array}$ \\
\hline $\begin{array}{l}\text { 3. Los sarrayns dien que en l'Alcorà } \\
\text { són noranta e nou noms de Deu, e } \\
\text { qui sabia lo centè sabria totes coses; } \\
\text { per que yo fas aquest libre de Cent } \\
\text { noms de Deu, los quals se, e per tot so } \\
\text { no's segueyx que sapia totes coses; e } \\
\text { assò fas a rependre lur falsa opinió. E } \\
\text { en est dictat pos molts noms qui són } \\
\text { pus propris a Deu, que alcuns que los } \\
\text { sarrayns a Deu aproprieen. }\end{array}$ & $\begin{array}{l}\text { 3. Asserunt Sarraceni in libro } \\
\text { Alkoram reperiri nonaginta nouem } \\
\text { Dei nomina, et quod, qui sciret } \\
\text { centessimum, omnia sciret. Quare ego } \\
\text { ex centum Dei nominibus quae Dei } \\
\text { gratia scio, hunc librum compono, } \\
\text { et non propter ea sequitur me omnia } \\
\text { scire, ut ex hoc redargui possit } \\
\text { Sarracenorum falsa opinio. Quin imo } \\
\text { in hoc tractatu quam plura ponuntur } \\
\text { nomina Deo magis propria quam sint } \\
\text { aliquam quam a Sarracenis tribuuntur } \\
\text { ipsi Deo. }\end{array}$ \\
\hline $\begin{array}{l}\text { 4. La manera que prepòs tenir en } \\
\text { est libre es que parle naturalment dels } \\
\text { noms de Deu qui simplament a él se } \\
\text { pertanynen; e de aquels noms qui a } \\
\text { Deu se pertaynen segons esguarda- } \\
\text { ment de creatura, que parle segons } \\
\text { so que als noms se pertayn segons } \\
\text { Deu e creatura. }\end{array}$ & $\begin{array}{l}\text { 4. Modus autem quem in hoc libro } \\
\text { seruare propono est ut de nomibus } \\
\text { simpliciter Deo pertinentibus natura- } \\
\text { liter loquar, et de nominibus [del.] illis } \\
\text { quae ipsi Deo [del.] pertinent loquar, } \\
\text { secundum respectum creaturae et } \\
\text { secundum quod conueniunt ipsi Deo. }\end{array}$ \\
\hline $\begin{array}{l}\text { 5. En cascú dels cent noms } \\
\text { preposam posar.x. verses, los quals } \\
\text { hom pot cantar. E assò fem per so } \\
\text { cor los sarraíns canten l'Alcorà en la } \\
\text { mesquita; per que aquests verses se } \\
\text { poden cantar segons que'ls sarraíns } \\
\text { canten. }\end{array}$ & $\begin{array}{l}\text { 5. Ponimus autem in quolibet } \\
\text { dictorum centum nominum decem } \\
\text { uersiculos, ut possint decantari ad } \\
\text { instar psalmorum ecclesiasticorum, } \\
\text { quod etiam facimus propter ea quod } \\
\text { Sarraceni ipsi decantant Alkoram } \\
\text { eorum. }\end{array}$ \\
\hline $\begin{array}{l}\text { 6. Aquest libre es bo a contemplar } \\
\text { e a conèxer Deus, e a provar la fe } \\
\text { cristiana, segons que en él apar; e es } \\
\text { libre de gran consolació e plaer. }\end{array}$ & $\begin{array}{l}\text { 6. Liber iste usui esse potest ad } \\
\text { contemplandum et cognoscendum } \\
\text { Deum et comprobandam fidem } \\
\text { christianam, prout in eo apparet, et } \\
\text { ad habendum magnam consolationem } \\
\text { et solatium et non parum utilis ad } \\
\text { praedicandum. }\end{array}$ \\
\hline
\end{tabular}


7. En aquest libre cové usar de alcuns vocables qui són en latin, sens los quals no'l poriem tan bellament e bonament fer : lo primer nom de Deu es Deus, segon es essencia, e axí dels altres segons que en les rúbriques apar.

8. Con Deus aja posada virtut en paraules, peres e erbes, quant, doncs, mays la posada en los seus noms! Per que yo conseyl que hom cascú dia los.c. noms de Deu, e que escrits ab sí los port.

9. Con hom aurà dit un capítol, digua hom aquesta lausor, en qui's conté la essencia de Deu, e les sues dignitats e persones divines, e la humanitat de Crist, e la virginitat de nostra Dona :

Laus et honor essentiae Dei et diuinis personis et dignitatibus earum. Et recordemur et amemus Iesum Naçarenum et Mariam uirginem matrem eius.

Aquesta lausor se diu enaxí com la Gloria Patri.

10. Aquests verses rimam en vulgar per so que mils hom los pusca saber de cor; e no fem forsa si en alcuns verses ha mais sillabes que en altres; car assó sostenim per so que meylor materia puscam posar en est libre. $\mathrm{E}$ ha major difficultat en posar tam subtil materia, [com ha en est libre om. $B N$ ], en rimes, que no es l'Alcorà posar en lo dictat en que es posat.

(ed. S. GalmÉS DE Fuentes, 1936, ORL XIX, 79-81)

Podríamos señalar en primer lugar que Ramon Llull compuso estos poemas en catalán para que fueran aprendidos de memoria con facilidad :

10. Aquests verses rimam en vulgar per so que mils hom los pusca saber de cor.

7. Necesse est autem in eo aliqua latina uocabula usurpare, sine quibus non posset aequi bene et pulchre consistere : primum nomen est Deus, secundum essentia, et sic de reliquis iuxta ordinem rubricarum.

8. Cum Deus uirtutem uerbis, lapidibus et herbis fuerit impartitus, quanto magis credendum est eam suis nominibus comunicasse! Quare consilium meum est ut ista centum nomina Dei recitet homo quotidie, et secum portet.

9. Quodlibet autem capitulum uice gloria Patri concludat, et terminet cum illa laude quae habetur in fine libri.

$<$ [78r] Laus repetenda in fine cuiuslibet psalmi :

Laus et honor essentiae Dei, personis et atributis diuinis et recolamus. Amen

Iesu Nazareno et Maria uirgini eius matri, et speramus et desideramus carnis resurrectionem et in celo coram Deo gratiam et sempiternam glorificationem. Amen>

10. Versus autem istos rithmice componimus ut melius possint memoria retineri, non tamen facimus uim in mensura aut aequali numero syllabarum, ut meliorem et altiorem materiam capere possint. Difficilius est autem de tam alta et subtili materia rithmice agere quam Alkoram dictasse eo stilo soluto quo procedit.

(Milano, Bibl. Ambrosiana, 81 Sup., fol. 1r-v, s. XVI-XVII; ed. propia)

.


y que debían ser pronunciados con el tipo de recitación cadencial que se utiliza en la psalmodia :

5. En cascú dels cent noms preposam posar.x. verses, los quals hom pot cantar.

Además, al final de cada composición, se debía cantar una alabanza (una lausor) de tornada :

9. Con hom aurà dit un capítol, digua hom aquesta lausor, en qui's conté la essencia de Deu, e les sues dignitats e persones divines, e la humanitat de Crist, e la virginitat de nostra Dona :

Laus et honor essentiae Dei et diuinis personis et dignitatibus earum. Et recordemur et amemus Iesum Naçarenum et Mariam uirginem matrem eius.

Aquesta lausor se diu enaxí com la Gloria Patri.

Esta misma tornada o lausor fue utilizada igualmente en el op. 70 Contemplatio Raymundi 7,9 [París agosto de 1297] ${ }^{3}$ y al final de l'op. 79 Cant de Ramon [París 1299 o Mallorca 1300] ${ }^{4}$, ambas obras hechas aproximadamente diez años después del op. 38 Cent noms de Déu. Después volveros a esta lausor.

Ramon Llull, en fin, había pensado que los poemas podían ser psalmodiados durante la ceremonia religiosa, como hacen los sarracenos con el Corán :

5. En cascú dels cent noms preposam posar.x. verses, los quals hom pot cantar. E assò fem per so cor los sarraíns canten l'Alcorà en la mesquita; per que aquests verses se poden cantar segons que'ls sarraíns canten.

Curiosamente la tradición lulística cumplió este desideratum, ya que ha trascendido a uno de los manuscritos catalanes que conservan los Cent noms de Déu [Palma, Societat Arqueològica Lul-liana, ms. 2], en donde encontramos añadidas indicaciones que distribuyen la lectura de los poemas durante la recitación litúrgica. Así, antes del primer poema, dedicado a Dios, incluye en rojo «Primera feria matines» [fol. 4r]; antes del quinto, dedicado al Padre, la indicación «Prima» [fol. 9r]; antes

3. Ed. S. GALMÉs, ORL XVIII, pp. 417-418: «(...) sufficere non possum ad dicendum, sicut nec sufficio ad cogitandum, nec ad regraciandum tibi pro gracia predicta, cum dico: "Laus et honor essencie Dei, et diuinis personis, et dignitatibus earum, et recordemur et amemus Iesum Nazarenum, et Mariam uirginem matrem eius"; et hanc laudem semper dicam in eleuacione corporis gloriosissimi domini nostri Iesu Christi ». Trad. propia : [(...) no alcanzo a pronunciar, como no alcanzo a pensar ni a agradecertelo por la mencionada gracia, cuando digo : "Alabanza y honor a la esencia de Dios, a las Personas divinas y a sus dignidades. Y recordemos y amemos a Jesús de Nazaret y a su Madre, la virgen María]", y diré simpere esta alabanza en elevación del cuerpo de nuestro gloriosísimo Señor Jesucristo] ».

4. Ed. S. GalmÉs, ORL XIX, p. 260 ; ed. J. Batalla, 2004, p. 139. 
del séptimo, dedicado al Espíritu santo, «Tercia» [fol. 11v]; antes del noveno, dedicado al atributo Existente, «Sexta» [fol. 14r]; antes del decimotercero, dedicado al atributo Libertad, «Vespres» [fol. 18r]; antes del decimosexto, dedicado al atributo Vida, «Completa» [fol. 21r]; antes del decimoséptimo, dedicado a la Infinitud, «Segon maitines» [fol. 22r]; antes del 19, dedicado al atributo Bueno, «Prima» [fol. 25r]; etc. Este manuscrito incluye inequívocamente un explicit muy claro con la idea de psalmodia o psalterio : «Explicit psalterium Raymundi, in quo sunt centum nomina Christi uirtuosissima ualde» [fol. 118r] [Acaba el psalterio de Ramon, en el que hay cien virtuosísimos nombres de Cristo].

En otro caso, en el ms. de la Bibl. Colombina de Sevilla 7-6-41, la compilación de los nombres de Dios aparece en forma de imprecación a Dios, como explicit del op. 49 Liber de sancta Maria [Montpeller, 1290 ? $]^{5}$, fol. $211 \mathrm{r}^{6}$ :

Editus fuit iste liber per magistrum Raymundum Lulli de Maioricis et transcriptus Rome et completus die.via. nouembris.1429. Amen.

O Deus, o Essencia, o Unitat, o Trinitat, o Pare, o Fill (...) o Comensament, o Fi e Compliment, ages pietat de ta gent e beneesch-me ab tos noms cent ${ }^{7}$.

Ahora bien, para nuestra interpretación de la obra, es clave remarcar la detección de irregularidades que resultan de los análisis métricos ${ }^{8}$ : en el ejemplo escogido a continuación sobre la composición 8 . «O Singular! » se detecta, al lado de la regularidad de tercetos, irregularidades en el número de sílabas y en la métrica, en tanto que la rima, que es regularmente oxítona, oscila entre la fórmula asonante y consonante. Estas irregularidades, sin embargo, resultan ser una característica común de todas las composiciones de la obra :

\begin{tabular}{|l|l|}
\hline 8. O Singular! & 8. O Singularis! \\
\hline $\begin{array}{l}\text { 1. O Ens, qui estàs Singular } \\
\text { en infinir e eternar, } \\
\text { a Tu tot sol do mon amar! }\end{array}$ & $\begin{array}{l}\text { 1. O Deus, qui es Singularis } \\
\text { in infinire et aeternare, } \\
\text { Tibi soli trado meum amare! }\end{array}$ \\
\hline $\begin{array}{l}\text { 2. Molt major és eternitat } \\
\text { si està en singularitat } \\
\text { que si fos en dualitat. }\end{array}$ & $\begin{array}{l}\text { 2. Multo miror est aeternitas } \\
\text { si est in singularitate } \\
\text { quam si existerit in dualitate. }\end{array}$ \\
\hline
\end{tabular}

5. Ed. B. GARÍ, ROL XXVIII, aunque esta edición prescinde de anotar lo que aquí estamos destacando.

6. Se trata de la tabla de rúbricas de los Cent noms de Déu.

7. Traducción propia : «Este libro fue escrito por el maestro Ramon Llull de Mallorca, y fue acabado de copiar en Roma el 6 de noviembre de 1429. Amen. 1. ¡Oh Dios ! 2. ¡Oh Esencia ! 3. ¡Oh Unidad! (...) 99. ¡O Inicio ! 100. ¡O Fin y Cumplimiento !, ten piedad de tu pueblo y bendíceme con tus cien nombres ».

8. Ver la nota 2 . 


\begin{tabular}{|c|c|}
\hline $\begin{array}{l}\text { Axí com Déus és Singular en } \\
\text { finitat, } \\
\text { ové que sia Singular en eternitat, } \\
\text { er ço que en El agen egualtat. }\end{array}$ & $\begin{array}{l}\text { 3. Sicut Deus est Singularis in } \\
\text { infinitate, } \\
\text { oportet eum esse singularem in } \\
\text { aeternitate, } \\
\text { ut non careant in ipso aequalitate. }\end{array}$ \\
\hline $\begin{array}{l}\text { 4. Singular és Déus en infinir, } \\
\text { en eternar e en complir, } \\
\text { e en deificar e en unir. }\end{array}$ & $\begin{array}{l}\text { 4. Singularis est Deus in infinidando, } \\
\text { in aeternando et complendo, } \\
\text { in deificando et uniendo. }\end{array}$ \\
\hline $\begin{array}{l}\text { er e saviea e volentat } \\
\text { ritat, } \\
\text { són una unitat. } \quad 15 \\
\end{array}$ & $\begin{array}{l}\text { 5. In Deo sunt in sigularitates } \\
\text { potestas, sapientia et uoluntas, } \\
\text { in quantum existunt una unitas. }\end{array}$ \\
\hline $\begin{array}{l}\text { amor } \\
\text { r, } \\
\text { isor. }\end{array}$ & $\begin{array}{l}\text { Amare est singulare in amore } \\
x \text { amabili et amatore, } \\
t \text { idemmet est de laudatione. }\end{array}$ \\
\hline $\begin{array}{l}\text { 7. Singularment és granea bona per } \\
\text { bondat, } \\
\text { e singularment és amada } \\
\text { per volentat, } \\
\text { e materialment és creació de creat. }\end{array}$ & $\begin{array}{l}\text { 7. Magnitudo per bonitatem et singu- } \\
\text { laritatem bona } \\
\text { et per uoluntatem amatur } \\
\text { singulariter } \\
\text { et creatio de creato est materialiter. }\end{array}$ \\
\hline $\begin{array}{l}\text { 8. Dé } \\
\text { per s } \\
\text { encar }\end{array}$ & $\begin{array}{l}\text { anitatem, } \\
\text { itate. }\end{array}$ \\
\hline $\begin{array}{l}\text { 9. Si en Déus no fos singularitat } 25 \\
\text { de propria proprietat, } \\
\text { no fóra gran sa unitat. }\end{array}$ & $\begin{array}{l}\text { eo non esset singularitas } 25 \\
\text { a proprietate } \\
\text { esset in paruitate. }\end{array}$ \\
\hline $\begin{array}{l}\text { 10. Car Déus és singular en valor, } \\
\text { a Ell pertayn singular honor } \\
\text { que sia a totes major. } \\
\text { Laus et honor essentie Dei et diuinis } \\
\text { personis et dignitatibus earum. } \\
\text { Et recordemur et amemus Iesum } \\
\text { Naçarenum et Mariam uirginem } \\
\text { matrem eius. }\end{array}$ & $\begin{array}{l}\text { 10. Cum Deus sit singularis in ualore, } \\
\text { dignus est singulari honore } \\
\text { et ominibus modis maiore. } \\
\text { [om., sed cf. infra fol. } 78 r \text { ] } \\
\text { Laus et honor essentiae Dei, personis } \\
\text { et atributis diuinis et recolamus. Amen } \\
\text { Iesu Nazareno et Maria uirgini eius } \\
\text { matri, et speramus et desideramus } \\
\text { carnis resurrectionem et in celo } \\
\text { coram Deo gratiam et sempiternam } \\
\text { glorificationem. Amen }\end{array}$ \\
\hline -ORL XIX, & \\
\hline
\end{tabular}

9. Traducción propia del catalán (N. B. : mantengo los neologismos aparecidos en la obra, como por ejemplo infinir 'ser infinito', eternar 'ser eterno', característicos del 
Sin necesidad de concluir que se trata de poemas de poca calidad literaria, hay que remarcar que no son versos formalmente perfectos. La traducción latina (probablemente tardía), mantiene imperfecciones semejantes o, incluso, más abundantes, en tanto que no consigue, aunque lo intenta, mantener la rima.

Aun así, las imperfecciones formales detectadas venían ya reconocidas en el prólogo por su autor : en cuanto a las irregularidades en el número de sílabas :

10. (...) e no fem forsa si en alcuns verses ha mais sillabes que en altres; car assó sostenim per so que meylor materia puscam posar en est libre.

y en cuanto al uso de latinismos, en favor de la belleza poética y corrección del texto :

7. En aquest libre cové usar de alcuns vocables qui són en latin, sens los quals no'l poriem tan bellament e bonament fer : lo primer nom de Deu es Deus, segon es essencia, e axí dels altres segons que en les rúbriques apar.

El final del prólogo es, pues, algo más que una simple captatio :

10. E ha major difficultat en posar tam subtil materia, com ha en est libre, en rimes, que no es l'Alcorà posar en lo dictat en que es posat.

De acuerdo con su intención de hacerlo servir en la psalmodia, Ramon Llull compone el libro en vulgar :

10. per so que mils hom los pusca saber de cor

pero muestra la preocupación de mantener la composición bella (bel dictat) en la deseada vesión latina que pide que sea hecha por la Iglesia :

2. Soplec doncs al sant Payre Apostoli e als seynors cardenals que'l fassen posar en latí en bel dictat, car yo no li sabria posar, per so car ignor gramàtica ${ }^{10}$.

catalán de esta época y del (nuevo) lenguaje filosófico y teológico de Ramon Llull) : « 8. ¡Oh Singular! [1] ¡Oh Ente, que eres Singular | en infinir y eternar, | sólo a Tí doy mi amar! [2] Mucho mayor es la eternidad | si está en singularidad | que si estuviera en dualidad. [3] Así como Dios es Singular en infinitud, | es necesario que sea Singular en eternidad, | para que en Él haya igualdad. [4] Dios es Singular en infinir, | en eternar y en cumplir, | y en deificar y en unir. | [5] En Dios poder, sabiduría y voluntad | están en singularidad, | puesto que juntos hacen una unicidad. | [6] Amar es Singular en amor, de parte del que es amable y del amante, | y ello mismo motivo alabanza. [7] Singularmente en Él hay grandeza buena por bondad, singularmente es amada por voluntad | y materialmente es creación del creado. | [8] Dios ha adquirido humanidad, | para que en una singularidad | la Encarnación tenga más bondad. | [9] Si no hubiera en Dios singularidad | de propia propiedad, | no sería grande su unicidad. | [10] Pues Dios es singular en valor, | a Él le pertenece un honor singular | que es el mayor de todos. | Loanza y honor... su Madre.»|

10. Para A. GALMÉs DE Fuentes, Ramón Llull y la tradición árabe, Barcelona, 1999 , p. 11, este pasaje permite corroborar que «parece ser que, si Ramón Llull llegó 
En definitiva, en el op. 38 Cent noms de Déu Ramon Llull quiere superar la tradición coránica de los nombres de Dios (y del Corán mismo, tal y como veremos) con una composición en versos, pero que resultan justificadamente imperfectos. Se nos plantea, pues, el problema principal de la obra : ¿es que no va en contra de la finalidad de la obra una redacción en versos que resultan imperfectos? Para responder positivamente a esta pregunta, hay que profundizar en los temas principales que trata la obra : la tradición de los nombres de Dios y de la inimitabilidad del Corán. Pero resultará fundamentel tener en cuenta la idea de que los versos de esta obra puedan ser cantados a la manera en que los sarracenos psalmodian el Corán en la mezquita :

5. En cascú dels cent noms preposam posar.x. verses, los quals hom pot cantar. E assò fem per so cor los sarraíns canten l'Alcorà en la mesquita; per que aquests verses se poden cantar segons que'ls sarraíns canten.

Tengamos en cuenta, seguidamente, algunas circunstancias textuales que rodean las intenciones de esta obra de Ramon Llull.

\section{LA TRADICIÓN DE LOS NOMBRES DE DIOS}

Resulta evidente que Ramon Llull quiso imitar, para superarla, la tradición islámica de los 99 nombres de Dios o de los nombres más bellos (al-asmā'al-husnā). Además, Ramon Llull retomó el tema años más tarde, aunque ahora de manera prosaica y testimonial, en el op. 132 Liber de centum signis Dei [Pisa, mayo de 1308$]^{11} \mathrm{y}$ en el op. 149 Liber de nominibus diuinarum personarum $(=$ De Trinitate in Vnitate permansiue in essentia Dei) ${ }^{12}$ [Montpelier, abril de 1309]. Ninguna de estas dos obras basa su argumentación en los atributos divinos, pero los títulos dejan claro que Ramon Llull todavía pensaba en esta tradición islámica.

Antes de continuar, sería conveniente recordar brevemente en qué consiste la tradición islámica de los nombres de Dios, por lo que a un conocimento profundo del árabe, no alcanzó, en cambio, a dominar el latín, pues
así lo declara él mismo en Els cent noms de Déu» [y cita este mismo lugar]. Aunque
continúa reconociendo que "podríamos pensar que esta situación [sc. de desconoci-
miento del latín] habría sido superada más tarde, durante su estancia en París", recuerda
que todavía, en 1315, pedía ayuda en la traducción de sus obras del catalán al latín
(pp. 11-12). Y aun a continuación, se muestra convencido de que "En todo caso, si
Ramón Llull no llegó a tener perfecto dominio del latín, debieron ser, sin duda, superiores
sus conocimientos del árabe" (p. 12). Nuestro análisis, en cambio, va encaminado a
reconocer aquí un tópico luliano y coherente con el espíritu con el que compone, según
intentaremos demostrar a continuación.

11. Ed. A. MADRE, ROL XXII.

12. Ed. parcial de C. OtTAVIANO, Rivista di cultura 16 (1929), 289-290. 
recogemos primeramente el listado de atributos a los que Ramon Llull dedica sus composiciones poéticas :

\begin{tabular}{|l|l|l|l|}
\hline \multicolumn{2}{|c|}{$\begin{array}{c}\text { Cent noms de Déu } \\
\text { (ed. S. GALMÉs, ORL XIX) }\end{array}$} & \multicolumn{2}{c|}{$\begin{array}{c}\text { De centum nominibus Dei } \\
\text { (ms. Milano, Bibl. Ambrosiana, } \\
\text { 81 Sup.) }\end{array}$} \\
\hline 1. Deus & 51. Endressador & 1. Deus & 51. Director \\
\hline 2. Essencia & 52. Imperador & 2. Essentia & 52. Imperator \\
\hline 3. Unitat & 53. Elegidor & 3. Vnitas & 53. Elector \\
\hline 4. Trinitat & 54. Faedor & 4. Trinitas & 54. Factor \\
\hline 5. Payre & 55. Valor & 5. Pater & 55. Valor \\
\hline 6. Fil & 56. Seynor & 6. Filius & 56. Dominator \\
\hline 7. Sant Sprit & 57. Vensedor & $\begin{array}{l}\text { 7. Spiritus sanc- } \\
\text { tus }\end{array}$ & 57. Victor \\
\hline 8. Singular & 58. Graciant & 8. Singularis & 58. Gratia \\
\hline 9. Estant & 59. Misericor- & 9. Existens & 59. Misericordia \\
\hline 10. Obrant & 60. Piadós & 10. Agens & 60. Pius \\
\hline 11. Ens necessari & 61. Abondós & $\begin{array}{l}\text { 11. Ens necessar- } \\
\text { ium }\end{array}$ & 61. Abundans \\
\hline 12. Perseitat & 62. Rey & 12. Perseitas & 62. Rex \\
\hline 13. Libertat & 63. Humil & 13. Libertas & 63. Humilis \\
\hline 14. Simple & 64. Suau & 14. Simplex & 64. Suauis \\
\hline 15. Sant & 65. Membrat & 15. Sanctus & 65. Memoratus \\
\hline 16. Vida & 66. Loat & 16. Vita & 66. Laudatus \\
\hline 17. Infinitat & 67. Nomenat & 17. Infinitas & 67. Nominatus \\
\hline 18. Eternitat & 68. Onrat & 18. Aeternitas & 68. Honoratus \\
\hline 19. Tot & 69. Reclamat & 19. Totum & 69. Reclamatus \\
\hline 20. Bo & 70. Beneït & 20. Bonus & 70. Benedictus \\
\hline 21. Gran & 71. Servit & 21. Magnus & 71. Cui seruitur \\
\hline 22. Poder & 72. Temut & 22. Potestas & 72. Qui timetus \\
\hline 23. Saviea & 73. Pregat & 23. Sapientia & 73. Rogatus \\
\hline 24. Amor & 74. Differenciant & 24. Amor & 74. Distinctio \\
\hline 25. Virtut & 75. Concordant & 25. Virtus & $\begin{array}{l}\text { 75. Concordan- } \\
\text { tia }\end{array}$ \\
\hline 26. Veritat & 76. Equalant & 26. Veritas & 76. Aequans \\
\hline & & & \\
\hline
\end{tabular}




\begin{tabular}{|c|c|c|c|}
\hline 27. Gloria & 77. Innocent & 27. Gloria & 77. Innocens \\
\hline 28. Justicia & 78. Alt & 28. Iustitia & 78. Altus \\
\hline 29. Larguea & 79. Significat & 29. Largitas & 79. Significans \\
\hline 30. Forma & 80. Perseverant & 30. Forma & 80. Perseuerans \\
\hline 31. Produccio & $\begin{array}{l}\text { 81. Exemplifi- } \\
\text { cant }\end{array}$ & 31. Productio & $\begin{array}{l}\text { 81. Exemplifi- } \\
\text { cans }\end{array}$ \\
\hline 32. Bel & 82. Movent & 32. Pulcher & 82. Mouens \\
\hline 33. Jhesus & 83. Prenent & 33. Iesus & $\begin{array}{l}\text { 83. Comprehen- } \\
\text { dens }\end{array}$ \\
\hline 34. Creador & 84. Digne & 34. Creator & 84. Dignus \\
\hline 35. Recreador & 85. Esperat & 35. Recreator & 85. Expectatus \\
\hline 36. Glorificador & 86. Major & 36. Glorificator & 86. Maior \\
\hline $\begin{array}{l}\text { 37. Ressusci- } \\
\text { tador }\end{array}$ & 87. Amic & 37. Resuscitator & 87. Amicus \\
\hline 38. Salvador & 88. Desiderat & 38. Saluator & 88. Desideratus \\
\hline 39. Edificador & 89. Ferm & 39. Aedificator & 89. Constans \\
\hline 40. Sustenidor & 90. Leyal & 40. Sustentator & 90. Legalis \\
\hline 41. Exoïdor & 91. Present & 41. Exauditor & 91. Praesens \\
\hline 42. Ordenador & 92. Noble & 42. Ordinator & 92. Nobilis \\
\hline 43. Visitador & $\begin{array}{l}\text { 93. Entenció } \\
\text { principal }\end{array}$ & 43. Visitator & 93. Intentio \\
\hline 44. Consolador & 94. Procurador & 44. Consolator & 94. Procurator \\
\hline 45. Consellador & 95. Advocat & 45. Consulens & 95. Aduocatus \\
\hline 46. Confortador & 96. Invisible & 46. Confortator & 96. Inuisibilis \\
\hline 47. Defensador & 97. Inmortal & 47. Defensor & 97. Immortalis \\
\hline 48. Sanador & 98. Infallible & 48. Sanator & 98. Infallibilis \\
\hline 49. Castigador & $\begin{array}{l}\text { 99. Comensa- } \\
\text { ment }\end{array}$ & 49. Castigator & 99. Principium \\
\hline 50. Nudridor & 100. $\mathrm{Fi}^{13}$ & 50. Nutritor & 100. Finis \\
\hline
\end{tabular}

Creemos prácticamente imposible deducir la fuente árabe o modelo del listado que ha seguido Ramon Llull, visto que los atributos utilizados

13. 1. Traducción propia: 1 . Dios $\mid$ 2. Esencia $\mid$ 3. Unicidad $\mid$ 4. Trinidad $\mid$ 5. Padre 6. Hijo $\mid$ 7. Espíritu santo $\mid$ 8. Singular $\mid$ 9. Permanente $\mid 10$. Obrador $\mid 11$. Ente necesario 12. Perseidad $\mid$ 13. Libertad $\mid$ 14. Simple $\mid$ 15. Santo $\mid$ 16. Vida $\mid$ 17. Infinitud $\mid 18$. Eternidad $\mid$ 19. Todo $\mid 20$. Bueno $\mid 21$. Grande $\mid 22$. Poder $\mid 23$. Sabiduría $\mid 24$. Amor $\mid 25$. Virtud 
se pueden reconocer como traducción de más de una palabra árabe y que la relación de Llull está adaptada a la fe cristiana. Así, por ejemplo, el atributo aș-șamad obtenido inequívocadamente de Q. 112, 2 (ya que es un hapax coránico), se puede reconocer traducido por 8. Singular y 14. Simple, y, acudiendo a interpretaciones tradicionales, incluso en 3. Unicidad y 19. Todo ${ }^{14}$. Si consultamos sólo algunas de las traducciones de esta palabra ass-samad, obtenemos una colección de atributos ${ }^{15}$ : Robert de Ketton (1142-1143) : necessarium omnibus et incorporeum ${ }^{16}$; Alquindi (trad. lat. 1142-1143) : Deus unus est singularis solidus ${ }^{17}$; Marcos de Toledo (c. 1210) : eternus ${ }^{18}$. Y por el mismo Ramon Llull : neque habet parem $^{19}$.

En la piedad popular musulmana ha sido acogida una antigua tradición basada doblemente en los dichos del Profeta (hadit $)^{20}$ y en los

| 26. Verdad | 27. Gloria | 28. Justicia | 29. Generosidad | 30. Forma |31. Producción | 32. Hermoso |33. Jesús |34. Creador|35. Recreador|36. Glorificante|37. Resucitante | 38. Salvador | 39. Edificante | 40. Sustentador | 41. Ayudante | 42. Ordenante | 43. Visitante $\mid$ 44. Consuelo $\mid$ 45. Consejero $\mid$ 46. Confortante $\mid$ 47. Defensor $\mid$ 48. Sanador $\mid$ 49. Castigador $\mid$ 50. Nodrizo $\mid$ 51. Director $\mid$ 52. Emperador $\mid$ 53. Elector $\mid$ 54. Hacedor $\mid$ 55. Valor $\mid 56$. Señor $\mid 57$. Vencedor $\mid$ 58. Gratificante $\mid 59$. Misericordioso $\mid 60$. Piadoso $\mid$ 61. Abundante |62. Rey | 63. Humilde $\mid$ 64. Suave $\mid$ 65. Recordado |66. Alabado 67. Nombrado | 68. Honrado | 69. Reclamado | 70. Bendito | 71. Servido | 72. Temido | 73. Rogado $\mid 74$. Distinción $\mid 75$. Concordante $\mid 76$. Igualitario $\mid 77$. Inocente $\mid 78$. Alto |79. Significante $\mid$ 80. Perseverante $\mid$ 81. Ejemplificante $\mid$ 82. Moviente $\mid 83$. Tomador | 84. Digno | 85. Esperado | 86. Mayor | 87. Amigo | 88. Deseado | 89. Constante 90. Leal | 91. Presente | 92. Noble | 93. Primera intención | 94. Procurador | 95. Abogado | 96. Invisible | 97. Inmortal | 98. Infalible | 99. Principio | 100. Fin.

14. En nuestra opinión, no es posible, pues, la afirmación hecha por J. HATEM, Sobreamor. Ausiàs March, Ibn Zaydûn, Ibn 'Arabî, Ramon Llull, Santa Coloma de Queralt, 2011, p. 65, cuando dice que Ramon Llull añadió al listado de 99 nombres árabes el término 'ish q de la mística musulmana, traducido por 88. Deseado (o Deseo), ya que no se puede distinguir con claridad, excepto en casos contados, los términos provenientes del árabe de los aportados por Ramon Llull.

15. Puede verse un estudio de este hapax y otros ejemplos de traducción griega y latina en Chr. SimELIDIS, « The Byzantine Understanding of the Qur'ānic Term al-șamad and the Greek Translation of the Qur'ān », Speculum 86 (2011), pp. 887-913.

16. Se trata de la primera traducción latina del Corán, publicada por Th. BIBLIANDER, Machumetis Saracenorum principis eiusque successorum uitae ac doctrina... s.l. [Basilea], 1543 (citado en el vol. I, p. 188).

17. Se trata de la traducción latina de la epístola de al-Kindī, ed. F. GonZÁLEZ MuÑoz, Exposición y refutación del Islam. La versión latina de las epístolas de al-Hāšimī y al-Kind̄̄, Univ. da Coruña, 2005.

18. Se trata de la segunda traducción latina del Corán, elaborada por Marcos de Toledo c. 1210, ed. de N. Petrus Pons, Liber Alchorani quem Marcus canonicus Toletanus transtulit, Universitat Autònoma de Barcelona, 2004 (tesis doctoral).

19. Op. 195 Liber de participatione christianorum et sarracenorum I, ROL XVI, p. 247 , lin. $44-72$.

20. El hadit principal es el que dice que «Dios tiene noventa y nueve nombres -cien menos uno-, y quien los guarde en la memoria entrará en el Paraíso », comentado 
comentarios al Corán $(t a f s i ̄ r)^{21}$ que encontró y dedujo ${ }^{22}$ del texto sagrado 99 atributos o apelativos de Dios, que, sustantivados, configuran la lista de 99 nombres de Dios o, como dicen en árabe, de «los nombres más bellos» (al-asmā' al-husnā). Pero el origen de esta tradición, efectivamente, radica en el Corán mismo [cf. Q. 20, 8 y 59, 24 : «¡Dios! ¡No hay más dios que Él! Posee los nombres más bellos»]. Puesto que el listado es deducido, las tradiciones ofrecen variantes, de manera que, sumados todos, el conjunto de la literatura piadosa islámica conoce más de 100 nombres. En todo caso, la recitación psalmódica es siempre una lista de 99 nombres, ya que toda tradición considera que el nombre 100 permenecerá oculto hasta el encuentro con Dios. Además, para ayudarse en la recitación de los nombres de Dios, el musulmán utiliza el tașbìh, una especie de rosario de 99 o 33 cuentas (en este útimo caso, naturalmente, hay que utilizarlo tres veces), objeto que siempre ha formado parte de la vida cotidiana del mundo islámico.

Del prólogo del op. 38 Cent noms de Déu se desprende que Ramon Llull relacionaba correctamente la tradición de los nombres de Dios con la lectura del Corán :

3. Los sarrayns dien que en l'Alcorà són noranta e nou noms de Deu, e qui sabia lo centè sabria totes coses

Sin embargo, como también dice Ramon Llull en el prólogo y se puede constatar en esta obra, algunos apelativos de los Cent noms de Déu no forman parte de la tradición islámica, como son, evidentemente, 4. Trinidad o 33. Jesús, sino que

3. E en est dictat pos molts noms qui són pus propris a Deu, que alcuns que los sarrayns a Deu aproprieen.

La introducción de estos atributos cristianos explica una de las finalidades principales de la obra : superar el contenido o tema (materia) del Corán, ya que este - se entiende - no recoje los nombres más adecuados a Dios, como son los citados 4. Trinidad o 33. Jesús :

2. a significar que enaxí com yo fas libre de meyllor materia que l'Alcorà, pot esser altre home qui aquest libre pos en axí bel dictat com l'Alcorà.

Hay que destacar, además, que Ramon Llull desvela los 100 nombres de Dios, y no se queda en los 99, lo cual es, per se, refutatorio.

por D. GIMARET, Les noms divins en Islam, exégèse lexicographique et théologique, Paris, 1988, pp. 51-68.

21. Comentado por D. Gimaret, Les noms divins..., pp. 69-83.

22. En resumen se puede decir que en el Corán no se encuentran en forma de atributo (adjetivo o aposición) los 99 nombres, sino algunos menos. El resto del listado, que, como decimos, es variable, son derivados de raíces verbales. 
Queda claro, pues, que una intención de la obra es denegar o anular el valor gnoseológico de la misma tradición islámica :

3. per que yo fas aquest libre de Cent noms de Deu, los quals se, e per tot so no's segueyx que sapia totes coses; e assò fas a rependre lur falsa opinió.

\section{LA INIMITABILIDAD DEL CORÁN}

Como demostración del carácter sagrado del Corán y, por lo tanto, como palabra de Dios, de su inimitabilidad, una cierta tradición islámica mantenía que el Libro no podía haber sido compuesto por Muhammad, basándose en el argumento que el Profeta era analfabeto ${ }^{23}$. Ramon Llull recoje claramente esta tradición en el op. 11 Llibre del gentil e dels tres savis IV, 3 cuando el Sarraceno argumenta que «Mafumet era home lec qui no sabia letres, e Deus revellá-li l'Alcorá, qui es libre de gran saviea e qui es lo pus bell dictat qui sia ni qui eser pusca ${ }^{24} \gg$, continuando, igual que en el prólogo de los Cent noms de Déu (prol. $2)$ : « cor tots los omens qui son, ni $\cdot$ ls angels ni $\cdot$ ls demonis, no purien ffer tan bell dictat con es l'Alcorá, qui es nostra $\operatorname{lig}^{25}$ ». Recordemos que, habiendo sido dictado y reproducido en boca del Profeta, y, por lo tanto, siendo de transmisión oral, la tradición dice que el texto coránico fue compilado y editado por el tercer califa, 'Uthmān, a veces también por el primero Abū Bakr. Ante todo ello, la literatura medieval de refutación del islam argumenta que la belleza del texto árabe es debida a un buen poeta y no a Dios. Este argumento, encaminado a destruir el carácter sagrado y la inimitabilidad del Corán, fue esgrimido igualmente por Ramon Llull de mantera clara en el op. 8 Doctrina pueril 71, 9 : «(...) i un sarraín que havia nom Abubecre [sc. Abū Bakr, el primer califa después de Muhammad] successor de Mafumet, qui fé escriure 1'Alcorà en belles paraules dictades a.vii. trobadors $(\ldots)^{26} \gg$. Pero lo reconocemos nuevamente en el prólogo del op. 38 Cent noms de Déu,

23. Esta tradición está también basada en el mismo Corán, sobre todo en relación con las interpretaciones de Q. 96, en donde queda explícito que Muhammad no sabía leer.

24. Ed. de A. BonNER, NEORL II, p. 165. Traducción propia : «Mahoma era un hombre ignorante que no sabía letras y Dios le reveló el Corán, que es libro de gran sabiduría y que es el dictado más bello que hay y que pueda haber ».

25. Op. 11 Llibre del gentil e dels tres savis IV, 3, (ed. A. BONNER, NEORL II, p. 165). Trad. propia : «pues ninguno de los hombres que hay, ni los ángeles ni los demonios, podrían hacer tan bello dictado [sc. estilo] como hay en el Corán, que es nuestra Ley $\gg$.

26. Op. 8 Doctrina pueril 71, 9 (ed. J. MedINA, ROL XXXIII, p. 352). Trad. propia : « (...) y un sarraceno llamado Abū Bakr, sucesor de Mahoma, que hizo escribir el Corán en bellas palabras dictadas a siete trobadores $»$. 
cuando dice que es posible que un hombre haya sido el autor del Corán, es decir, sea Mahoma o los poetas de las cortes de los primeros califas que editaron el Corán :

2. a significar que enaxí com yo fas libre de meyllor materia que l'Alcorà, pot esser altre home qui aquest libre pos en axí bel dictat com l'Alcorà.

Ramon Llull acude en más de una ocasión, antes y después ${ }^{27}$ de la redacción del op. 38 Cent noms de Déu, a la refutación de esta tradición milagrosa que evidenciaba la inimitabilidad del Corán. De las obras anteriores, podríamos citar el op. 8 Doctrina pueril 28 (Palma, 1274-1276), el op. 11 Llibre del gentil e dels tres savis ${ }^{29}$ (Palma, c. 1274-1283); y también en las fechas aproximadas a la redacción del op. 38 Cent noms de Déu, según encontramos en el op. 39 Liber Tartari et Christiani ${ }^{30}$

27. Matizamos, pues, la opinión de S. Garcias PALOU, Ramon Llull y el islam, Palma de Mallorca, 1981, p. 66 : «Pero, en el libro de los Cent Noms de Déu, no habla del milagro del Corán, que tardó mucho en mencionar [el subrayado es nuestro]. No lo hizo, en efecto, hasta el año 1305, en el Liber de fine, y, el año 1309, en el Liber de adquisitione Terrae Sanctae».

28. Op. 8 Doctrina pueril 71, 6 (Palma, 1274-1276, ed. J. MedINA, ROL XXXIII, p. 350): «i puis [Mafumet] deia que sant Gabriel li venia, que li aportava paraules de Déu, les quals són en lo llibre qui és appellat Alcorà, e que ell per la gran santedat de sant Gabriel i de les paraules no es podia sostenir, i per açò gitava's en terra ». Trad. propia : " Además [Mahoma] decía que le venía san Gabriel, quien le traía palabras de Dios que están en el libro llamado Corán, y que Mahoma, debido a la gran santidad de Gabriel y de las palabras, no se podía aguantar y por eso se agitaba en el suelo [sc. en relación con los trastornos que sufría el Profeta durante las revelaciones, identificados por cierta tradición como ataques de epilepsia] ».

29. En abundancia a la nota anterior n. 24. Op. 11 Llibre del gentil e dels tres savis IV, 4 passim. (ed. A. BONNER, NEORL II, pp. 167-169, v.gr. IV, 4, 1) : « Mafumet fo home lec qui no sabia letres, e l'Alcorà es lo pus bell dictat que sia ni qui eser pusca. On, si no fos per volentat e per obra de Deu, Maffumet no pogra fer ni dictar tan bell dictat ni tan ordenades paraules con son celles del Alcorá ». Trad. propia : « Mahoma era un hombre ignorante que no sabía letras y el Corán es el más bello dictado que hay o que pueda haber. Por lo cual, si no fuera por voluntad de Dios, Mahoma no podría haber hecho ni dictado tan bello dictado ni unas palabras tan ordenadas como son las del Corán ».

30. Op. 39 Liber Tartari et Christiani III, 10-12 [ed. propia, en prensa para la col. Traducció de la Obra Llatina de Ramon Llull, Santa Coloma de Queralt (TOLL)] : [29] - Audi, Tartare - inquit Saracenus - : Lex nostra in pulcherrimum dictamen uersa est, non enim est in uniuerso mundo tanta pulchritudo dictaminis, unde uidetur legem nostram a Deo esse. Omnes enim homines quotquot uiuunt nunquam inuenire possent nec dictare dictamina pulchriora.

[30] Tunc ait Tartarus illi : "In pulchritudine dictaminis modica est uis facienda : in ueritate latet omnis uirtus uerborum. Vnde, si de lege tua scis alias rationes hiis fortiores, quae minime continent ueritatem, eas desidero toto corde".

[31] Tunc Saracenus siliuit. Trad. propia : «[29] - Escucha, Tártaro, dijo el Sarraceno. Nuestra religión ha sido expuesta en un dictado bellísimo, pues no hay en todo el mundo un dictado tan bello, de donde se deduce que nuestra ley es de Dios. Pues todos los hombres que viven nunca pueden encontrar ni dictar unos dictados tan bellos. 
(1288); y después, en el op. 122 Liber de fine ${ }^{31}$ (Montpeller, 1304), en el op.146 Liber de acquisitione Terrae sanctae ${ }^{32}$ (Montpeller, 1309). En todos aquellos lugares Ramon Llull argumenta la refutación del Corán, aunque reconoce siempre su bello estilo («bell dictat»), en base a su pretendida inspiración divina por medio del ángel Gabriel y en base a su estilo inimitable - es decir, al que nadie puede poéticamente alcanzar-.

Per lo tanto, en el prólogo 2 del op. 38 Cent noms de Déu debemos reconocer, al menos, dos argumentos de tradición islámica :

1) El Corán es un «bel dictat».

2) El Corán es una obra de Dios, dictada por Él al Profeta Muḥammad y, por ello, inimitable.

$\mathrm{Al}$ inicio del prólogo y, por lo tanto, en un lugar muy destacado, encontramos que la obra sobre los Cent noms de Déu está monográficamente destinada a refutar el Corán. Y, como en otras ocasiones, que Ramon Llull quiere demostrar como falsa la inimitabilidad del Corán.

2. Con los sarraíns entenen provar lur lig esser donada de Deu, per so car l'Alcorà es tam bel dictat que no'l poria fer nuyl hom semblant d'él, segons que els dien, yo, Ramon Luyl indigne, me vuyl esforsar, ab ajuda de Deu, fer aquest libre, en qui ha meyllor materia que en l'Alcorà, a

[30] Entonces le dijo el Tártaro :-A la belleza de un dictado hay que atribuir una fueza adecuada : en la verdad se oculta toda la fuerza de las palabras. Por lo tanto, si conoces otras razones sobre tu ley más fuertes que éstas que no contienen la verdad, las deseo escuchar de todo corazón.

[31] Entonces el Sarracenó se quedó callado ».

31. Op. 122 Liber de fine I, 2 (ed. A. MADRE, ROL IX, p. 257) : « Saraceni credunt habere unum miraculum necessarium siue uerum ; ratione cuius affirmant eorum legem esse ueram. Et hoc miraculum est, eo quia dicunt Alcoranum fore in supremo gradu dictaminis sic dictatum, in tantum quod homo ipsum dictasse non potuisset. Sed fuit missus per ipsum Gabrielem in os ipsius Macometi, et hoc Dei dictamine sic uolentis. Et sic uocant uerbum Dei Alcoranum. Dictamen uero multum ornatum est; ego uidi. Sed subiectum siue materia est trufatoria atque falsa et multis falsitatibus adornata; sicut est in pluribus cantilenis de actibus luxuriae adornatis. Ratione cuius leuiter illud, quod dicunt esse miraculum, potest destrui et annullari ». Trad. propia : "Los sarracenos creen tener un solo milagro necesario o verdadero, por lo que afirman que su ley es verdadera. Y ello es un milagro, porque dicen que el Corán fue el más alto estilo que ha sido dictado, en tanto que un hombre no pudo haberlo dictado; sino que fue enviado por el mismo Gabriel en boca del mismo Mahoma, y en el estilo que Dios quiso. Y por eso dicen que el Corán es palabra de Dios. Su estilo es muy ornado, yo lo ví, pero su tema o materia es ridícula y falsa y adornada con muchas falsedades, como se ve en muchos pasajes sobre actos adornados de lujuria. Por esa razón fácilmente aquello que dicen que es un milagro puede ser destruido y anulado ».

32. op. 146 Liber de acquisitione Terrae sanctae [ed. E. Kamar, Studia Orientalia Christiana 6 (1961), p. 119] : «Omnes homines de mundo non possent dictamen facere ita pulcrum, nec etiam angeli, et sic supponunt quod est a Deo datum et sic datum est uerum ». Trad. Propia : « Entre todos los hombres del mundo no pueden hacer un estilo tan hermoso, ni tampoco los ángeles, y así suponen que fue dado por Dios y, como fue dado, es verdadero $»$. 
significar que enaxí com yo fas libre de meyllor materia que l'Alcorà, pot esser altre home qui aquest libre pos en axi bel dictat com l'Alcorà. E assò fas per so que hom pusca argüir als sarraíns que l'Alcorà no es dat de Deu; ja sia que sia bel dictat. Emperò deim que aquest libre, e tot be, es donat de Deu, segons que dir se cové. [los subrayados son nuestros]

Para entender el contenido de esta refutación, hay que recordar ahora brevemene el tema de la imitabilidad ( $i$ ’djaz) del Corán : para la tradición literaria islámica, el estilo cadencial del Corán y su expresividad condensada, a menudo vehemente, resultan imposibles de reproducir ${ }^{33}$. Así, el elevado estilo del Corán, expresado, de acuerdo con el tempo de la revelación y de la fijación del texto ${ }^{34}$, entre la prosa y la prosa rimada ( $s a \underline{d j}$ ), se sitúa en el máximo modelo de la literatura clásica árabe. La prosa rítmica del texto árabe busca el énfasis en ciertas sílabas que dan igual cadencia y rima, siendo desigual el número de sílabas intermedias entre estas rimas. De hecho, existen ediciones del Corán en lengua árabe preparadas para la correcta lectura litúrgica, en las que se indican con colores la intensidad de la pronunciación de las sílabas, para asegurar su prosa cadencial. Este estilo (dictamen) elevadísimo, resulta per se una evidencia de que es un libro revelado al Profeta Muhammad por Dios en lengua árabe ${ }^{35}, \mathrm{y}$, por lo tanto, del hecho milagroso de su existencia y redacción, tal como debe creerse por el mismo Corán, según confiesa en más de una ocasión. Así, por ejemplo, en Q. 10, 37-38 ${ }^{36}$ :

33. Por ejemplo, el traductor catalán del Corán, M. Epalza, busca aproximarse al estilo original con un resultado que describe así (trad. propia del catalán) : «Hemos escogido un estilo musical que no sea ni poesía formal, muy estructurada, ni prosa conceptual, en la que sólo cuentan los conceptos analíticos. El resultado que buscamos es hacer una prosa rimada (basada en un ritmo musical y renunciando a la rima del árabe coránico), con un ritmo bastante flexible y variable, ya que también lo son - flexibles y variables - los recursos estilísticos y literarios del Corán » (M. EPALZA, Alcorà, Barcelona, 2001, p. 1162).

34. Es bien conocido que el estilo coránico varía entre las suras reveladas en $\mathrm{La}$ Meca y las reveladas en Medina, al mismo tiempo que algunos elementos rítmicos son atribuibles a la transmisión del texto, como recientemente ha recordado la presentación propedéutica de F. Déroche, El Corán, col. Davinci ¿qué sé ? n. 29, Barcelona, 2011, pp. $44-48$.

35. La expresión «en lengua árabe clara » es recurrente en el Corán, como por ejemplo en Q. 12,$2 ; 20,113 ; 39,18 ; 41,3 ; 42,7 ; 43,3$. Este mismo hecho abunda en su inimitabilidad (por ser palabra de Dios, en árabe) y explica igualmente que la tradición islámica no haya considerado el Corán sino en lengua árabe, de manera que las traducciones no son el Corán, sino que deben ser tenidas como comentarios al Corán.

36. Por dar apoyo al comentario recogido de M. Epalza en la nota 33, recogemos aquí su traducción formal de este mismo lugar Q. 10, 37-38 :

[37] Aquest Alcorà no pot ser cap recitació que s'hagi inventat

algú que no sigui Déu, $\mathrm{Al} \cdot$ là.

Ans al contrari, és una bona confirmació, molt detallada,

del que és cert en l'escriptura, Bíblia sagrada,

els llibres sants que posseïu, 
[37] Este Corán no puede haberlo inventado nadie fuera de Dios. No sólo eso, sino que viene a confirmar los mensajes anteriores y a explicar detalladamente la Escritura, exenta de dudas, que procede del Señor del universo. [38] O dicen : «Él lo ha inventado». Di : «Si es verdad lo que decís, ¡traed una sura semejante y llamad a quien podáis, en lugar de llamar a Dios!».

Apreciando este estilo especial del Corán, es posible ver, en las escasas ocasiones en que Ramon Llull lo cita durante su producción, que se muestra clara su aproximación a la poética coránica. Así, en el prólogo del op. 11 Llibre del gentil IV ${ }^{37}$, la traducción de la basmalla - imprecación que encabeza las suras del Corán - y de la sura 1 :

En nom de Deu misericordiòs, misericordejant

[en árabe : r-rạ̣mani-r-rahīm]

al qual sia donada laor,

cor es seynor del mon;

en ell aor e en ell me confiy,

cor ell es endresament

de la dreturera carrera de salut.

[en árabe : ș-șirāta-l-mustaqīm șirāța-l-ladīna]

Y en el op. 195 Liber de participatione christianorum et sarracenorum I, (ROL XVI, 247, lin. 44-72), de la sura 112, 3-4 :

Deus non est gignens neque genitus [ar. lam yalid wa lam yūlad] neque habet parem

Vista esta característica formal del Corán, es decir, la recitación en forma de prosa rimada, hay que volver a la intención que Ramon Llull mantiene sobre esta obra de ser cantado, tal como hacen los sarracenos con el Corán en la mezquita :

5. En cascú dels cent noms preposam posar.x. verses, los quals hom pot cantar. E assò fem per so cor los sarraíns canten l'Alcorà en la mesquita; per que aquests verses se poden cantar segons que'ls sarraíns canten.

Teniendo en cuenta las caraterísticas estructurales de la prosa poética del Corán, se explica mejor y de hecho se acaba de aceptar que las imperfecciones formales que hemos detectado en el op. 38 Cent noms

sense que hi hagi cap dubte, ara,

perquè us ve de Déu, Al·là, que és Senyor de l'univers.

[38] Ells gosen dir : "Se l'ha inventada!".

Digues [profeta] : "Si sou sincers i voleu dir la veritat,

porteu ací només un text, o una sura,

semblant a aquestes de l'Alcorà,

$\mathrm{i}$ invoqueu qui us pugui fer aquest miracle

i no sigui Déu. p. 159).

37. Op. 11 Llibre del gentil e dels tres savis IV, pròleg (ed. A. BONNER, NEORL II, 
de Déu en realidad no sean tales imperfecciones, sino un modo de imitación de la tradición árabe.

No es necesario, sin embargo, detenerse en la influencia árabe. De hecho, en la tradición del verso románico existe la diferencia entre la «recitación», es decir, la pronunciación cadencial de los versos, y la «cantilación» o lectura en voz alta de un texto en prosa, con una entonación y una cadencia musical que subraya la puntuación del texto. Este segundo tipo de entonación sobre la prosa o cantilación es reconocible en la lectura y pronunciación del Corán, en la que está claro que la cantilación no es música ${ }^{38}$. De manera similar ocurre con la pronunciación de la psalmodia en la liturgia, en donde el número de sílabas no es necesariamente regular, sino que se busca una acadencia regular en la recitación. De aquí que tanto los versos de los Cent noms de Déu, escritos para ser cantados, como la lausor que acompaña a cada uno de ellos, puedan mantener irregularidades silábicas y de rima. De hecho, la indicación explícita sobre la tornada que acompaña a cada uno de los poemas :

9. Aquesta lausor se diu enaxí com la Gloria Patri

aproxima toda la composición a la recitación psalmódica, como ha hecho con la citada tornada.

\section{CONCLUSIONES}

Por lo tanto, la estrategia de refutación del Corán que Ramon Llull utiliza en el op. 38 Cent noms de Déu es tan sencilla que, incluso, resulta ingenua : para superar al Corán, que contiene «tam subtil matèria», pero que se presenta con una forma literaria imprecisa, és decir, en «lo dictat en que es posat», Ramon Llull acude básicamente a dos argumentos : 1) hacer un libro que contenga «meyllor materia que en l'Alcorà », es decir, loando a Dios con nombres que le son más propios que los que se encuentran en el Corán, como Jesús o Trinidad; y 2) tratar la materia «en rimes», cosa que «ha major difficultat».

Habiendo escogido una forma literaria formalmente más precisa como es la poesía psalmódica, Ramon Llull cree haber superado al mismo Corán, expresado en su opinión en una forma literariamente insuficiente o imperfecta, cosa que no le correspondía a un libro inspirado por Dios y, por lo tanto, quedaría refutado como milagro y libro sagrado. Es decir, demostraría que el Corán es un libro hecho por un hombre y no por Dios. Todo ello lo dice programáticamente en el prólogo :

2. me vuyl esforsar, ab ajuda de Deu, fer aquest libre, en qui ha meyllor materia que en l'Alcorà, a significar que enaxí com yo fas libre de meyllor

38. Agradezco al profesor Antoni Rossell (UAB) la aclaración sobre la recitación y la cantilación del texto medieval, a quien también agradezco haberme permitido acceder a sus notas de trabajo sobre este asunto. 
materia que l'Alcorà, pot esser altre home qui aquest libre pos en axí bel dictat com l'Alcorà. E assò fas per so que hom pusca argüir als sarraíns que l'Alcorà no es dat de Deu; ja sia que sia bel dictat.

De esta manera creemos poder dar respuesta a la pregunta que nos hemos formulado antes : ¿es que no va en contra de la finalidad de su obra una redacción con versos que resultan formalmente imperfectos? Una vez expuestos nuestros argumentos, no debemos ocultar que Juan Vernet precisamente, uno de los grandes traductores del Corán al castellano - ya llegó a la misma conclusión, diciendo : «Estas últimas palabras de Llull [en referencia la final del prol. 10] indican bien claro lo que pretendía : escribir en prosa rimada (en árabe $s a d j$ ) y en versículos de varia longitud como en el Corán, pero con rimas más marcadas que en las de éste ${ }^{39}{ }^{\prime}$.

Esta conclusión, profundizando todavía en las observación de Juan Vernet, conlleva la distinción en Ramon Llull cuando utiliza la rima dentro de una composición poética formalmente perfecta, de cuando utiliza la rima dentro de una composición prosaica (prosa rimada) o de una poesía formalmente imperfecta. El primer caso agruparía las composiciones más habituales en Ramon Llull como poeta medieval; el segundo caso, sin embargo, no sólo se encuentra en el op. 38 Cent noms de Déu; es también la forma de prosa rimada del op. 1 Compendium logicae Algazelis/Lògica del Gatzell, en donde, sin ir más lejos de los primeros versos, se percibe claramente :

Deus, per far a vos honrament

de lògica tractam breument,

lo qual es compendi novell,

en mon enteniment appell

que translat de latí en romanç

en rimes en mots qui son plans,

per tal que hom puscha mostrar

lògica e philosoffar

a cels qui no saben latí

ni aràbich : per que vos mi

endreçats, Sènyer, en saber

en bona entenció haver.

[ed. ORL I, S. GALMÉS, 3] $]^{40}$

39. J. VERNET, (1967), « Observacions sobre el llibre Oracions de Ramon», Estudis Romànics 10, 85-89 [reimpr. en J. Vernet, De 'Abd al-Rahmān I a Isabel II, Barcelona, 1989, 29-33], cit. p. 86, citadas en trad. propia del catalán.

40. Trad. propia : «Dios, para haceros honra, | de lógica tratamos brevemente, | cosa que es un compendio nuevo, | y convoco a mi entendimiento | que traduzca de latín en romance | en rimas de palabras agudas, | para que cualquiera pueda enseñar | lógica y filosofía $\mid$ a quienes no saben latín $\mid$ ni árabe : porque vos me | dirigís, Señor, en saber $\mid \mathrm{y}$ tener buena intención ». 
Probablemente, pues, no sería incorrecto relacionar esta técnica de prosa rimada, como vemos, influenciada por la tradición coránica al mismo tiempo que por la psalmodia de la liturgia cristiana y por la cantilación poética medieval, con otras obras, como con el op. 89 Oracions de Ramon [Barcelona, 1299] $]^{41}$, con el op. 77 Arbre de filosofia d'amor [Paris, 1298], y con los versets del op. 21b Llibre d'amic e amat [dentro del op. 21 Blaquerna, Montpelier c. 1274-1283] ${ }^{42}$, todas ellas muy próximas formal y temáticamente entre sí.

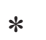

41. El caso de la prosa rimada del op. 89 Oracions de Ramon ha sido analizado per J. RuBió BALAGUER, « Sobre la prosa rimada en Ramon Llull », Estudios dedicados a Menéndez Pidal, Madrid, 1954, en vol. V, pp. 307-318, acudiendo a varios pasajes, como el cap. XVII, 1 [utilitzado la ed. de S. GALMÉs, ORL XVIII, pp. 345-346] :

Senyors àngels qui, Déus amats e en ell estats glorios e salvats! Esguardats sajús e vejats com lo poble de Deu, que vos tant amats, està en vayl tenebrosa e en mar tribulada e perillosa, e ajudatsnos contra los mals àngels e contra nostres greus peccats.

$\mathrm{O}$ bien ibid. XVII, 4

... en Deu amar honrar beneyr e servir ; e siats de nos colones en nos sostenir, per ço que per gracia de Deu, ab vostra ajuda, puscam nostres peccats delir, e Deu amar honrar e servir

42. En donde la influencia árabe (en este caso sufí) es manifiesta, segun el preámbulo que se lee en el cap. 99 del op. 21 Blaquerna [ed. S. GALmÉs, ENC 74, 10] : « Dementre considerava en esta manera Blanquerna, él remembrà com una vegada, com era apostoli, li recomtà un sserray que los serrayns an alcuns hòmens religiosos, e, enfre los altres e aquells qui són més preats enfre ells, són unes gents qui han nom sufies, e aquells han paraules d'amor e exemplis abreuyats e qui donen a home gran devoció ; (...) ell preposà a fer lo libre segons la manera demunt dita, e dix a l'ermintà que se'n retornàs a Roma, e que en breu temps li trametria, per lo diaque, lo Libre de Amich e Amat, per lo qual puria multiplicar frevor e devoció en los ermitans, los quals volia enamorar de Déu ». Trad. propia : « Mientras así pensaba Blaquerna, recordó cómo una vez, cuando era Papa, le contó un sarraceno que los sarracenos tienen algunos hombres religiosos y entre ellos unos que son más apreciados que se llaman sufís, que tienen palabras de amor y ejemplos abreviados y que dan al hombre gran devoción ; (...) [Blaquerna] se propuso hacer el libro según la manera mencionada, y le dijo al ermitaño que volviera a Roma, y que en breve le enviaría, a través del diácono, el op. 21b. Libro del amigo y del amado, con el que podría multiplicar su fervor y devoción en los ermitaños, a los cuales quería enamorar de Dios ».

Ya en el cap. 100 (es decir, en el prólogo del op. 21b) : «E en la benedicció de Déu, Blanquerna començà son libre, lo qual departí en aytants versses con ha dies en l'ayn. E cascú vers basta a tot.i. dia a contempar Deú, segons la Art del Libre de contemplació ». Trad. propia : «Y en la bendición de Dios, Blaquerna empezó su libro, que dividió en tantos versos como días tiene el año. Y cada verso basta al día para contemplar a Dios, según el arte del op. 2 Libro de contemplación ».

Por otra parte, el análisis de la prosa del op. $21 \mathrm{~b}$ Libre d'amic $i$ amat, hace evidene una estructura poética o rítmica, como por ejemplo, en las metáforas o, como dice su autor, en los versos : [ed. d'A. SOLER, ENC B 13] : « [6] Dix l'amich a l'amat :- Tu qui imples lo sol de resplandor, umple mon cor d'amor. Respòs l'amat :- Sens compliment d'amor no foren tos ulls en plor, ni tu vengut en est loch veer ton amador. » Trad. propia : 
Ad libitum. El op. 38 CENT NOMS DE DÉU EN El CONTEXTO Literario DE REFUTACIÓN DEL ISLAM

Viendo el conjunto de literatura medieval de refutación del islam, la argumentación y la forma que utiliza Ramon Llull en su obra Cent noms de Déu resultan extraordinarios. Si bien es cierto que Ramon Llull mantiene la argumentación tradicional que desautoriza las doctrinas islámicas de la sacralidad del Corán y de su revelación al Profeta Muhammad - y, por tanto, al hecho de su reconocimiento como Profeta -, ahora Ramon Llull no se limita simplemente a denostar estas doctrinas, como hace largamente la tradición latina de refutación, sino a demostrar de manera fehaciente que las verdades que pretenden mantener los sarracenos son falaces. Lo quiere hacer con la acción de superar la inimatibildad del Corán, añadiendo el argumento que los nombres de Dios de la tradición islámica son insuficientes para identificar a Dios verdadero, $\mathrm{y}$, por lo tanto, refuta que es un libro revelado al mismo tiempo que deduce que Mahoma es un falso profeta.

Acudir al argumento ad intra de la tradición islámica parece una innovación de su época. Ahora sabemos que el mismo Ramon Llull acudió a fuentes árabes para redactar la exposición que mantiene el sarraceno en el libro IV del op. 11 Llibre del gentil i dels tres savis ${ }^{43}$. Su contemporáneo Riccoldo de Montecroce, habiendo pasado muchos años en el Próximo Oriente, citó doctrinas y costumbres islámicas con un cierto respeto y autenticidad, aunque también acompañadas de argumentos de desautorización. Y su coetáneo Ramon Martí también acudió al texto coránico para refutarlo. Pero Ramon Llull, en el op. 38 Cent noms de Déu, no sólo parace haber acudido a fuentes árabes, sino, más todavía, parece haberlas imitado con la acción de la escritura y el hecho literario de la composición poética. De esta manera, ad intra, y no sólo con la autoridad de la lógica basada en la doctrina cristiana, Ramon Llull pretende desautorizar que el reconocido bel dictat sea un argumento para mantener el hecho milagroso del Corán y que éste sea un dictado de Dios. Y esta manera de proceder en contra de las doctrinas islámicas es realmente remarcable, porque no sólo es una innovación, sino que no conocemos ninguna tradición posterior que lo haya vuelto a hacer. De hecho, no hay nadie más en occidente quien se haya autodenominado christianus arabicus.

Óscar de la CRUz PALMA

Universitat Autònoma de Barcelona

\footnotetext{
«Dijo el amigo al amado : - Tu que llenas el sol de resplandor, llena mi corazón de amor. Respondió el amado : - Sin llenado de amor, tus ojos no estarían en llanto y tu no habrías venido a esta lugar a ver a tu amado ».

43. Para ello, ver el estudio de introducción de Ó. de la Cruz Palma para la ed. del op. 11 Liber de gentili et tribus sapientibus, ROL XXXVI.
} 


\section{NOTA DE APOYO A ESTE TRABAJO}

Obras poéticas de Ramon Llull :

I. op. 1 Compendium logicae Algazelis/Lògica del Gatzell : Montpelier o Mallorca, c. 1265-1271/1272.

II. A vós, Dona Verge Santa Maria (dentro del op. 21 Blaquerna, Montpelier, c. 1276-1283).

III. Sènyer ver Deus, rei gloriós (dentro del op. 21 Blaquerna, Montpelier, c. 1276-1283).

IV op. 21b Llibre d'amic e amat/Liber amici et amati (libro VI de op. 21 Blaquerna).

V. op. 23 Lo peccat d'Adam/De peccato Adami: Montpelier o Mallorca, c. 1274-1283.

VI. op. 30 Regles introductòries a la pràctica de l'Art demostrativa : Montpelier 1283-1285 (?) [no confundirlo con el op. 30a Regulae introductoriae in prancticam Artis demonstratiuae, que es una traducción latina libre del op. 30, en prosa].

VII. op. 38 Cent noms de Déu/Centum nominibus Dei : Roma, 1288.

Otras propuestas de datación : A. R. Pasqual, Vindiciae Lullianae, Aviñón, 1778, vol. I, p. 168, A. I. Peirats, «El Liber de centum nominibus Dei ... », p. 297 : 1285; R. Hughes, «Deification/Homification and the doctrine of intentions : internal chirstological evidence for re-dating Cent noms de Déu», Studia Lulliana 41 (2001), 111-115, A. Bonner, Base de dades Ramon Llull, Centre de Documentació Ramon Llull (Universitat de Barcelona) : http ://orbita.bib.ub.edu/llull/ : 1292 (?)

VIII. op. 50 Hores de nostra Dona sancta Maria : loc. (?), 1290-1293 (?). IX. op. 51 Plant de nostra Dona santa Maria : loc. (?), 1290-1293 (?). X. op. 63 Lo Desconhort : Roma, 1295.

XI. op. 69 Proverbis/Liber prouerbiorum : Roma, 1296 (?).

[XII op. 77 Arbor philosophiae amoris/Arbre de filosofia d'amor : Paris, octubre 1298].

XIII. op. 79 Cant de Ramon : Paris, 1299 o Mallorca, 1300.

XIV. op. $87+88$ Lo dictat/Dictatum Raimundi et eius Commentum : Barcelona, 1299.

[XV. op. 89 Oracions de Ramon : Barcelona, 1299.

XVI. op. 90 Medicina de pecat, Medicina peccati : Mallorca, juliol 1300.

XVII. op. 96 Applicatio artis generalis/Aplicació de l'Art general : Mallorca, marzo 1301.

XVIII. op. 142 Proverbis d'ensenyament: (?), 1309.

XIX. op. 189a Del concili : Paris, octubre 1311.

NB. Hemos añadido a la lista los ítems IV y XII, por su naturaleza con vocaciónd e prosa rítmica. 
R. D'Alòs-Moner, Ramon Llull, Poesies, col. ENC 3, Barcelona 1925, pp. 10-13 y J. MASSÓ TORRENTS, Repertori de l'Antiga ... p. 271, clasifican las obras poéticas en tres grupos :

Poesías líricas de carácter trobadoresco (II, III, XIX);

poesías de metro épico francés (VI, IX, X);

poesías de tradición popular (I, V, VII, VIII, XI, XII, XIII, XIV, XVI, XVII, XVIII)

a las que se pueden añadir los textos escritos en prosa rimada (IV, XII, XV).

\section{Manuscritos Del OP. 38 CENT NOMS DE DÉ $U^{44}$}

versión catalana :

Vaticano, Apostolica, Ottob. lat. 542 (XIV). 90r-v

Vaticano, Apostolica, Ottob. lat. 845 (XIV). 2-41v

Palma, SAL, 2 (XIV). 1-118

Palma, BP, 1025 (XIV/XV). 85v-86 [fragmento]

Vaticano, Apostolica, Chigi lat. E.IV.118 (XIV/XV). 6v-7v (2v-3v)

Sevilla, BC, 7-6-41 (XV). 211ab

Madrid, BNE, 11559 (XV). 1-98v

Roma, Isidoro, 1/43 (XV 3r quart). 15-57

Roma, Isidoro, 1/71 (XV final). 41rb

Barcelona, BUB, 59 (XV final). 1-104

Palma, SAL, 9, I (XVI). 9-81v [acéfalo]

Palma, SAL, Aguiló 110 (XVI-XVII). 1-55

Vaticano, Apostolica, Vat. lat. 10036 (1615). 279v-305

Munic, SB, Clm. 10596 (XVII). 12-46

Palma, AD, Causa Pia Lul·liana 16 (XVII). 2-55; 58-98vv

versión latina :

Milano, Ambrosiana, N 81 Sup. (XVI). 1-79

Palma, AD, Causa Pia Lul·liana 16 (XVII). 2-55 ; 58-98v

EDICIONES DEL OP. 38 CENT NOMS DE DÉ $U^{45}$ :

Rosselló, 1859 = Obras rimadas de Ramon Lull, ed. Jeroni Rosselló, (Mallorca : Pere Josep Gelabert, 1859), 176-304.

Alòs-Moner (1925) = Ramon Llull, Poesies, ed. Ramon d'Alòs-Moner, col. ENC 3 (Barcelona : Barcino, 1925), 34-41. [fragmento]

44. Relación tomada de A. Bonner (dir), Base de Dades...

45. Por orden de aparición, según A. BonNER (dir.), Base de Dades.. 
RiQuer, Antologia = Antologia general de la poesia catalana, ed. Martí de Riquer, Josep Maria Miquel i Joan Teixidor, (Barcelona : Quaderns Literaris 100-101, 1936), 15-16. [fragment]

ORL XIX (1936), 75-170 (ed. S. GALMÉs)

OE = Ramon Llull, Obres essencials, intr. Joaquim Carreras i Artau, Miquel Batllori, Tomàs Carreras i Artau i Jordi Rubió i Balaguer, I (Barcelona : Selecta, 1957 i 1960), 1287-9. [fragmento]

Romeu, Poesies $(1958)=$ Ramon Llull, Poesies, ed. Josep Romeu i Figueras, (Barcelona : Selecta, 1958), 55-60. [fragmento]

Romeu, Poesies $(1988)=$ Ramon Llull, Poesies, ed. Josep Romeu i Figueras, "Biblioteca Universitària" 8 (Barcelona : Enciclopèdia Catalana, 1988), 32-8. [fragmentos]

Miralles, Antologia $=$ Joan Miralles i Monserrat, Antologia de textos de les illes balears. Volum I: Segles XIII-XVI, pr. Joan Martí i Castell, (Institut d'Estudis Baleàrics - Publicacions de l'Abadia de Montserrat, 2006), 93-95. [fragmento]

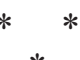

Óscar de la Cruz Palma, L'opus 38 Les Cent noms de Dieu de Raymond Llull, un poème anti-coranique.

Dans son op. 38 Cents noms de Déu (écrit en 1288 et traduit en latin comme le De centum nominibus Dei), Raymond Llull offre une centaine de poèmes de louange à Dieu sur la base de cent attributs ou vertus divins. Il s'agit donc d'une œuvre de piété, conçue pour être psalmodiée pendant les heures de prière. En effet, d'après l'examen des manuscrits, il s'avère que les poèmes étaient répartis selon les heures liturgiques chrétiennes. Mais en même temps, Raymond Llull s'y attaque au thème islamique des cent noms de Dieu (al-asmā'al-husnā), objectif qui apparaît clairement exprimé dans le prologue. La méthode qu'emploie Llull est unique dans le panorama médiéval : afin de réfuter le thème des cents noms de Dieu, il ne se limite pas à le dénigrer ou à l'opposer aux auctoritates. D'autre part, il met en œuvre une façon particulière d'adopter les formes littéraires islamiques : ainsi dans son op. 21b Llibre d'amic e amat, une œuvre insérée comme chapitre 99 à l'op. Romanç d'Evast e Blaquerna, il déclare suivre le modèle des soufis; dans le quatrième chapitre de l'op. 11 Llibre del gentil $i$ dels tres savis aussi, il met dans la bouche du sarrasin certains principes doctrinaux de l'islam empruntés directement de la tradition arabe, quoique appartenant à un courant plus populaire que ceux qui forment la profession des cinq piliers de l'islam. 
La méthode de Llull consiste à imiter littérairement un thème puisé directement dans la littérature islamique, adaptant au catalan la forme littéraire arabe (en l'occurrence, dans une forme poétique qui fait appel un à un aux noms de Dieu), afin de démontrer que la chose n'est pas propre aux musulmans. Les arguments de réfutation que Llull emploie sont donc internes à l'islam. Ce sont, essentiellement, les suivants : 1) si le thème implique initialement que les musulmans connaissent seulement 99 noms supposant que le nom 100 est connu au moment de la rencontre avec Dieu, Ramon Llull démontre qu'il connaît les 100 noms sans pour autant être musulman. Dans ce cas, la supériorité que Llull prétend affirmer à propos des noms de Dieu réside dans la connaissance de certains «noms de Dieu» reconnus comme tels par le christianisme, comme, par exemple, le poème 4 . Trinité ou le 5 . Fils, qu'il considère comme authentiques et inconnus ou mal compris par l'islam. 2) Si le thème implique qu'on fasse appel au Coran, puisque les 99 noms de Dieu proviennent d'épithètes coraniques, et que de surcroît la belle cadence de la langue coranique (le bell dictat auquel fait référence Ramon Llull) est si sublime que le Coran devient inimitable, alors Llull surenchérit en disant qu'il fera un livre encore meilleur, ce qui lui permet de réfuter cet autre argument. Dans ce sens, les indications sur l'intonation des poèmes du livre comportent des éléments de prosodie musicale qui ne sont pas un simple ornement poétique, mais un élément d'imitation de la prose cadentielle qui caractérise le texte arabe du Coran. 3) Enfin, si le prophète Mahomet ne peut pas être l'auteur du Coran (ni, par conséquent, l'inventeur de telles épithètes pour Dieu) parce qu'il était ignare, et que l'ignorance de Mahomet, loin d'être quelque chose de l'ordre du dénigrement devient donc une preuve aux yeux des musulmans du miracle de la révélation du Coran, avec ce texte Llull entend démontrer que n'importe quel homme (lui-même, en l'occurrence) peut atteindre ce style et ainsi réfuter l'argument islamique.

En somme, ce que prétend Llull est de démontrer de façon fiable la fausseté de la croyance islamique selon laquelle le Coran est un texte révélé et inimitable. Ainsi, Ramon Llul attaque en connaissance de cause l'un des principaux fondements de l'Islam, à savoir, la nature du texte coranique. Mais le plus remarquable est qu'il ne se limite pas à une simple réfutation, mais prétend également assimiler les formes de l'islam afin d'offrir un type de réfutation ad intra qu'on trouve difficilement chez d'autres auteurs contemporains ou postérieurs.

(Original espagnol rédigé par O. de la Cruz Palma) 